\title{
Retsensioon Jaan Laasi raamatu „Teadus diktatuuri kütkeis. Eesti teadusest ja kórgharidusest natsionaalsotsialistliku ja sovetliku teaduspoliitika raames. Epikriis" (Tallinn: Argo, 2010. 504 lk) kohta
}

Anu Raudsepp, Hillar Toomiste

Iga raamatu puhul on olulised eesmärk, autori teadmised ja oskused seda saavutada ning reaalsed tulemused. Jaan Laas on võtnud ette väga tähtsa teema Eesti teadusest ja kõrgharidusest 1940-1991 ning püstitanud sama kaaluka eesmärgi, rõhutades vajadust antud valdkonna „tähelepaneliku analüüsi ja üksikasjaliku läbikaalumise”, sh eriti tollastele teadusega seotud isikutele „tasakaalustatud ja ajalooliselt õiglase hinnangu andmise järele” (Ik 5).

Raamat koosneb viieteistkümnest erineva mahuga peatükist, millest pea pooled (7) on väga õhukesed (7-17 lk), mõned paarikümneleheküljelised ja ülejäänud kuus ulatuslikud (42-56 lk). Teose ülesehituses on selge, kronoloogiline printsiip (1918-1940, 1940-1941, 1941-1944) jälgitav kolme esimese peatüki puhul. Järgnevad kaksteist osa pretendeerivad küll ajalisele ülevaatele 1944-1991, kuid erinevate teemade käsitlemise rõhuasetus jääb valdavalt stalinismi aega, mis moodustab kokku umbes kolmveerandi kogu töö mahust (peatükkidena 9). Pealkirjad ei vasta alati sisule, nii pole 11. peatükis „Survepoliitika kunstija pedagoogikakõrgkoolides ning harukondlikes teadusasutustes" pedagoogikakõrgkoolidest juttu.

Teose mahtu (504 lk) on arvukate korduste (enamasti kahekordsete, vahel isegi kolmekordsete - näiteks Hiroshima ja Nagasaki aatomipommi plahvatuste kirjeldused Ik 135, 136, 194) abil kunstlikult suurendatud. Võib arvata, et teksti korrektne toimetamine vähendanuks lehekülgede arvu. Näide korduste stiilist ja sisust:

Lk 176: „Tänapäevane aatomiallveelaev on oma eriotstarbelise aparatuuri, võimsate relvasüsteemide ning olemuslikult erinevate energialiikide akumulatsiooni ja rakendamise ülikeeruline kompleks. Kõik selle superrelva koostisosad ja jõuallikad - tuumaenergia, elekter, keemiline elektrienergia ning ründerelvade lõhkelaengud - on paigutatud kompaktselt ühte soomuskapslisse."

Lk 201-202: „Uueaegsed aatomiallveelaevad olid juba 1980. aastate alguseks kujunenud eriotstarbelise aparatuuri, võimsate relvasüsteemide ning olemuslikult erinevate energialiikide akumulatsiooni ja rakendamise ülikeerulisteks kompleksideks. Kõik selle superrelva koostisosad ja jõuallikad - tuumaenergia, elekter, keemiline ja soojusenergia - on ründerelvade lõhkelaengus paigutatud kompaktselt ühte soomuskapslisse."

Kolme peatüki $(1,9,13)$ nappi leheruumi vähendatakse ka illustratsioonide abil. Sealhulgas täidavad esimese peatüki seitsmest lehest lausa nelja põhiruumi fotod, kusjuures jääb arusaamatuks Eesti Vabariigi aegse ülikooli illustreerimine nõukogudeaegse sümboolikaga rüütatud ülikooli peahoone fotoga. 
Peatükid tuginevad vähemalt kolmandiku osas ühele väljaandele. Peamiselt põhineb „Teadus diktatuuri kütkeis” kümmekonnale raamatule, nende seas mõned nõukogudeaegsed ${ }^{1}$ ja üks Välis-Eesti väljaanne ${ }^{2}$ ning mõned taasiseseisvunud Eesti ajal ilmunud eesti uurijate tööd ${ }^{3}$ ning üks Venemaa kogumik. ${ }^{4}$ Uusi, sh eesti uurimusi, mis raamatu teemaga seonduvad, napib. ${ }^{5}$

Viitamisega on väga palju probleeme. Paradoksaalselt esineb isegi viide sellisele Helmut Piirimäe kirjutisele ${ }^{6}$, mida tema tööde bibliograafias ei leidu. ${ }^{7}$ Raamatule on aga üldiselt omane vähene viitamine, mis tekitab eriti palju küsitavusi rohkete statistiliste andmete usaldusväärsuses. Korrektsete näidete kõrval esineb ridamisi erinevaid taunitavaid viitamise viise. Esiteks moonutab Laas tsiteeritud teose algset sisu. Näiteks: ta viitab Kaurile, justkui oleks see kirjutanud, et Saksa okupatsiooni ajal vallandati osa õppejõude, kes olid „kommu-

1 Jaan Laas. Teadusaeg. Teadusarendusest Eestis. Tallinn: Eesti Raamat, 1989; Tallinna Polütehniline Instituut 1936-1986. Tallinn: Valgus, 1986; Tartu Ülikooli ajalugu. III. Koostanud Karl Siilivask ja Hillar Palamets. Tallinn: Eesti Raamat, 1982.

2 Eesti riik ja rahvas II maailmasõjas. X. Stockholm: Kirjastus EMP, 1962.

3 Toomas Karjahärm, Helle-Mai Luts. Kultuurigenotsiid Eestis. Kunstnikud ja muusikud 1940-1953. Tallinn: Argo, 2005; Indrek Jürjo. Pagulus ja Nõukogude Eesti. Vaateid KGB, EKP ja VEKSA arhiividokumentide põhjal. Tallinn: Umara, 1996; Lembit Raid. Vaevatee. Tartu Ülikool kommunistlikus parteipoliitikas aastail 19401952. Tartu: Tartu Ülikooli Kirjastus, 1995; Kaljo-Olev Veskimägi. Nõukogude unelaadne elu. Tsensuur Eesti NSV-s ja tema peremehed. Tallinn: Tallinna Raamatutrükikoda, 1996; Kaljo-Olev Veskimägi. Kuidas valitseti Eesti NSV-d: Eestimaa Kommunistliku Partei Keskkomitee büroo 162 etteastumist 1944-1956 vaatemängude ja sissejuhatusega. Tallinn: Varrak, 2005; Luuramisi: salateenistuste tegevusest Eestis XX sajandil: artiklite ja dokumentide kogumik. Koostanud Tiit Noormets. Tallinn: Umara, 1999.

4 Repressirovannaja nauka. Võpusk II. Rossiiskaja Akademija Nauk. 1994.

5 Mõningaid näiteid: Väino Sirk. Züge der stalinistischen Politik in Bezug auf die estnische Bildungselite. Forschungen zur baltischen Geschichte. I. Herausgegeben von Mati Laur und Karsten Brüggemann. Tartu: Akadeemiline Ajalooselts, 2006; Priit Pirsko. Eesti arhiivinduse sovetiseerimine 1940-1941. - Eesti NSV aastatel 1940-1953: Sovetiseerimise mehhanismid ja tagajärjed Nõukogude Liidu ja Ida-Euroopa arengute kontekstis. Tartu: Eesti Ajalooarhiiv, 2007; Anu Raudsepp. Lõssenkism ja Tartu Ülikooli bioloogiaosakond. - Ajalooline Ajakiri. 2009, 1/2, Ik 179-196; Toomas Karjahärm, Väino Sirk. Kohanemine ja vastupanu. Eesti haritlaskond 1940-1987. Tallinn: Argo, 2007; Eesti ajalugu. V. Vabadussõjast taasiseseisvumiseni. Peatoimetaja Sulev Vahtre, tegevtoimetajad Ago Pajur ja Tõnu Tannberg. Tartu: IImamaa, 2005; The sovietization of the Baltic States, 19401956. Edited by Olaf Mertelsmann. Tartu: Kleio ajalookirjanduse sihtasutus, 2003; Aigi Rahi-Tamm. Arhiivid Nõukogude repressiivaparaadi teenistuses. „Poliitvärvingute” kartoteek Eestis 1940-1956. - Ajalooline Ajakiri 2009, nr 1/2, Ik 123-153.

6 Raamatus: H. Piirimäe. Mõningaid probleeme teaduslikust ekspertiisist. Nõukogude arhiivinduse 50. aastapäevale pühendatud juubelikonverentsi materjalid, Riia, 1968.

7 Vt: Die baltischen Länder und der Norden. Festschrift für Helmut Piirimäe zum 75. Geburtstag. Herausgegeben von Mati Laur und Enn Küng in Verbindung mit Stig Örjan Ohlsson. Tartu: Akadeemiline Ajalooselts, 2005, Ik 522-564. 
nistlikult meelestatud, rahvuslikult meelestatud, saksavastased" (Ik 75, kordusena Ik 448-449). Tegelikult ütleb Kauri, et vallandati need õppejõud, kes „olid kuulunud komparteisse, olnud kompartei liikme kandidaadid, avaldanud end probolshevistlikult, või saksavastaselt". 8

Teiseks kasutab Laas teiste autorite töid ilma viitamata, esitades sealseid seisukohti oma järeldustena. Mõned näited. Laas (Ik 344): „On ilmne, et „üliõpilasgrupi” vangipanek oli mõeldud intelligentsi ja kunstnikkonna hirmutamiseks [---]” ja Karjahärm, Luts: ${ }^{9}$ "IImselgelt oli „üliõpilasgrupi“ vangipanek mõeldud intelligentsi ja esmajoones kunstnike hirmutamiseks."

Laas (Ik 414, katkend pikemast viitamata lõigust): „Aastatel 1981-1985 toimus Eestis kuus kohtuprotsessi avalike vastupanuliikujate üle. Nõukogudevastase tegevuse eest mõisteti vangilaagrisse ja asumisele kokku üheksa isikut [---]" ja Viktor Niitsoo: ${ }^{10}$ "Aastail 1981-1985 toimus Eestis kuus kohtuprotsessi avalike vastupanuliikujate üle, kus nõukogudevastase tegevuse eest mõisteti vangilaagrisse ja asumisele üheksa isikut."

Kolmandaks kasutab Laas arhiiviviiteid, mis langevad kokku eeskujuks olnud autorite samateemaliste käsitluste arhiiviallikate ja nende sõnastusega. Palju taolisi probleeme on seotud Indrek Jürjo kirjutistega. Näiteks esineb käesolevas raamatus Ik 213 arhiiviviide ERAF f 1, n 302, s 473 । 9-10: „Eelnimetatud K. Kortelaineni ettekandes rõhutati vajadust jätkata koostööd Balti Instituudiga. Ettekandes toodi ära selle koostöö oodatavad tulemused ja „võidud“ KGB seisukohalt. Toodi esile, et koostöö jätkamine ja laiendamine aitab edaspidi: mõjutada meile soodsalt Rootsi valitsus- ja akadeemilisi ringkondi, neutraliseerida balti pagulaskeskused, mida USA eriteenistused kasutavad ära nõukogudevastases tegevuses; arendada patriootlikku liikumist pagulaste hulgas; luua alaline kanal meie esindajate Rootsi viimiseks jne."

Indrek Jürjol on täpselt sama arhiiviviide sõnastuselt kokkulangeva ja äratuntava teksti juures: ${ }^{11}$ „Oma ettekande Iõpus teeb Kortelainen ettepaneku BI-ga teadus- ja kultuurisidemeid jätkata, et kasutada neid järgmistel eesmärkidel: mõjutada meile soodsalt Rootsi valitsus- ja akadeemilisi ringkondi; [---] neutraliseerida balti pagulaskeskused, mida USA eriteenistused kasutavad ära nõukogudevastases tegevuses; arendada patriootlikku liikumist pagulaste hulgas; luua alaline kanal meie esindajate Rootsi viimiseks."

8 Hans Kauri. E.V. Tartu Ülikool okupatsioonide ajal. - Eesti riik ja rahvas II maailmasõjas. X. Stockholm: Kirjastus EMP, 1962, Ik 52.

9 Toomas Karjahärm, Helle-Mai Luts, Ik 125-126.

10 Viktor Niitsoo. Vastupanu 1955-1985. Tartu: Tartu Ülikooli Kirjastus, 1997, Ik 140.

11 Indrek Jürjo. Pagulus ja Nõukogude Eesti. Vaateid KGB, EKP ja VEKSA arhiividokumentide põhjal. Tallinn: Umara, 1996, Ik 272. 
Teaduspoliitika käsitlemine eeldab kindlasti selle suunamise ja kontrollimise süsteemi selgitamist, milles näidatakse erinevate institutsioonide ülesandeid, teaduse rahastamist ja vaagitakse teadlaste võimalusi ettekirjutusi vältida. Käesolevast raamatust loogilist süsteemi välja ei loe.

Ebaselgused algavad juba mõistete defineerimise ja kasutamisega, kuigi teema olemuse mõistmise aluseks on adekvaatne arusaamine erinevatest terminitest. Raamatus on hulganisti omapäraseid mõistete defineerimise ja kasutamise viise, millest võib järgnevalt valiku iseloomulikke näiteid tuua. Stalinismi periodiseeringusse toob Laas novaatorlikult mõiste sõjajärgsed stalinlikud aastad (Ik 286). Antud mõiste määratlemisel on kõigepealt oluline, kui kaua kestsid autori arvates sõjajärgsed aastad, kuna ta käsitleb antud osas aega alates 1944. aastast kuni 1980. aastate keskpaigani, rääkimata sellest, kui pikka aega üldse sõjajärgseks ajaks traditsiooniliselt peetakse. Põhimõtteliselt võiks ju sõjajärgne aeg igavesti kesta, kui ei tule (loodetavasti) uut sõda. Paraku ei tunne ajalooteadus taolist terminit, küll aga kasutatakse sõjajärgse stalinismi mõistet. ${ }^{12}$

Laasi väitel „Laidoner küüditati N Liidu vangilaagrisse” (Ik 20), kuid küüditamine (inimeste vägivaldne ümberasustamine) ja arreteerimine (vahi alla võtmine) on kaks eri mõistet, vangilaagrisse saatmise puhul küüditamise mõistet ei kasutata.

Autor kirjutab Hans Kaurile viidates, et Saksa okupatsiooni ajal olevat kavatsetud luua Tartus ainus okupeeritud Baltimaade ja Valgevene klassikaline ülikool (Ik 75), kuid tegelikult nimetas Kauri „saksakeelset nelja teaduskonnaga (õigus-, arsti-, filosoofia- ja loodusteaduskond) ülikooli". ${ }^{13}$ Klassikalise ülikooli neli teaduskonda olid filosoofia-, usu- õigus- ja arstiteaduskond, loodusteaduskond ei sobi sellesse loetellu kohe kuidagi.

Laas kirjutab 1979. aasta NLKP KK määrusest „Ideoloogilise ja poliitkasvatustöö edasisest parandamisest” (Ik 173). Tegelikult NLKP KK otsus „Ideoloogiatöö ja poliitilise kasvatustöö edasisest parandamisest". ${ }^{14}$ Ideoloogiatöö on laiem mõiste, mille üks osa on ideoloogiline kasvatustöö.

Mitmetele mõistetele antakse raamatus hoopiski uus sisu. Nii on EKP Keskkomitee teaduse, koolide ja kultuuri osakonna juhataja ülendatud teadusjuhiks (Ik 218), kuigi nimetatud institutsiooni ülesanne polnud ju teadustöö, vaid hoopis ideoloogiline järelevalve.

\footnotetext{
12 Vt lähemalt stalinismiperioodi ajalisest määratlemisest: Tiiu Kreegipuu. Eesti kultuurielu sovetiseerimine: Nõukogude kultuuripoliitika eesmärgid ja institutsionaalne raamistik aastatel 1944-1954. - Eesti NSV aastatel 1940-1953: Sovetiseerimise mehhanismid ja tagajärjed Nõukogude Liidu ja Ida-Euroopa arengute kontekstis. Koostanud Tõnu Tannberg. Tartu: Eesti Ajalooarhiiv, 2007, Ik 355-358.

13 Hans Kauri. E.V. Tartu Ülikool okupatsioonide ajal. - Eesti riik ja rahvas II maailmasõjas. X. Stockholm: Kirjastus EMP, 1962, Ik 52.
}

14 Avaldati ka ajalehes Rahva Hääl 6. mail 1979. 
Eriti üllatav on segadus natsionaalsotsialistliku teaduspoliitika ajaliste raamide tundmises (see termin kajastub ju teose pealkirjaski): „[---] 1930. aastate lõpus jätkus füüsikute rahvusvaheline koostöö veel mitmesuguste rahvuslike teaduskonverentside ja külastuste raames. A. Hitleri võimuletulek Saksamaal muutis aga järsult teadusarendusliku olukorda kogu Euroopas." (Ik 143). Hitler tuli võimule 1933!

Kuna Jaan Laas vaatleb tehnikateadustega seotud küsimusi korduvalt, siis peaks ta hästi orienteeruma sellegi ala terminites. Ta nimetab, et tehnikateadused jagunevad 25 allsuunda (raamatus küll 23) ja 224 allvaldkonda (Ik 198-201). Kui tegemist on NSV Liidus kasutatud klassifitseerimisega, tuleks seda ka algallikale viidates selgelt öelda. Praegusel kujul tekitab taoline küsitav loetelu segadust ja jääb mulje, et autor on sellise jaotuse ise meelevaldselt välja mõelnud. Tehnikateaduste kohta on näiteks nimekad teadlased Eesti Entsüklopeedias 12 põhivaldkonda nimetanud. ${ }^{15}$ Põgus võrdlemine näitab erinevusi Laasi ja tehnikateadlaste käsitluse vahel: robotitehnika on entsüklopeedias elektrotehnika, Laasil masinaehituse ja masinaõpetuse osa; Laasil on elektroonika valdkonnad tahkiselektroonika, mikroelektroonika, vaakum- ja plasmaelektroonika, kvantelektroonika, elektroonika tehnoloogiaseadmestik (Ik 201), tehnikateadlastel aga pooljuhtelektroonika, elektroonikamaterjalide ning arvuti- ja süsteemitehnika valdkond jne. Pommuudisena on tehnikateaduste osaks saanud arhiivindus (Ik 200), töökaitse ja tuletõrje (Ik 201). Loetelu Iõpetav repliik „Tehnikateaduste võrgustiku ja selle sõlmpunktide puhul tuleb rõhutada, et suur osa sõjatehnika ja sõjateaduse arendamisega seotud spetsiifilistest rakendus-teaduslikest uurimisvaldkondadest on sellest kõrvale jäänud. Seega pole toodud loetelu täielik." (Ik 201) annab mõista, et tehnikateaduste all võiks veel nii mõndagi esitada. Katse anda sisu mõistetele tehnikateaduste võrgustik ja tehnikasõda mõjuvad tänapäevases kontekstis õõnsana.

Last but not least tekitab antud väljaandes segadusi mõiste ajaloolane määratlemine ja sellest tulenedes nende tegevusele Laasi poolt antud hinnangud. Raamatust kipub jääma mulje, et ajaloolasteks on loetud ka NLKP ajaloo uurijad. Nende puhul sobib võib-olla tõesti väide „põhijoontes kestsid ja püsisid sovetlikud ajaloovõltsingud ning sovetlik ajalookäsitlus ja -seletus kuni N Liidu lagunemiseni" (Ik 385). Ajalooteadlastel olid aga eelkõige olulised valdkonnad agraarsuhted ja talurahva ajalugu, keskaegne kroonikakirjutus, rahvastikuajalugu, kaubandus jm, mille saavutused on hinnatavad tänaseni ja edaspidigi. Varjutada paljude tunnustatud ajaloolaste töid ajaloovõltsinguteks nimetamisega on hämmastav, kui mitte öelda solvav. Raamatu lugemisel jäävad silma paljud eklektiliselt ühendatud refereeringud, nõukoguliku retoorikaga looritatud sisuline pealiskaudsus, nõrk allikakriitika ning teaduslikult põhjendamata, nõukogulikele arvamustele sarnanevad hinnangud.

15 Eesti Entsüklopeedia. 11. Tallinn: Eesti Entsüklopeediakirjastus, 2002, Ik 497-501. 
Raske on leida sisu paljudest taolistest lausetest: „Riigi ees seisvate teadus- ja tehnopoliitiliste küsimustega hakati tegelema riigi juhtimise kõrgeimal tasandil. Läbiviidud analüüside ja tegeliku praktika hinnangute alusel saadud tulemuste ning seisukohtade põhjal koostati järgnevatel aastatel rohkesti mitmesuguseid regulatsioone." (Ik 149, kordusena Ik 150)

Esitatud faktide tähendus jääb sageli pealiskaudsuse ja ebamäärasuse tõttu hoomamata, kuna nende tegelikku sisu pole avatud ja laiema taustaga seostatud. Mõned näited. Laas nimetab küll, et 1941. aasta suvel hävis Tartus sõjategevuse käigus 465000 raamatut, kuid ei selgita, millist kahju see Eesti teadusele tekitas. Ometi hävisid ju 10.-25. juulil 1941 Tartu sõjatulekahjus prof Hendrik Sepa, prof Gustav Suitsu, prof Peeter Tarveli, prof Albert Valdese, prof Ulrich Karelli, prof Olaf Silla jpt hindamatu väärtusega aastakümneid komplekteeritud erialased raamatukogud, teadustööde käsikirjad. ${ }^{16}$

Laas ütleb Saksa okupatsiooni aegset teaduselu käsitledes: „Kuna Saksamaa oli 1941. aastal vallutanud laialdased Eesti lähinaabruses asuvad Ingeri- Novgorodi- ja Pihkvamaa alad, tuli neis kujunenud rahvastikualane olukord täpsemalt fikseerida. Vallutatud aladel moodustasid okupatsioonivõimud vähemusrahvustest inimeste hulga arvelevõtmiseks registreerimiskomisjonid. 1942. ja 1943. aastal tegutsesid sellised komisjonid Ingerimaal ja Oudova aladel ning nende koosseisu kuulusid ka eesti teadlased G. Ränk, P. Ariste, M. Toomse ja mitmed teised. Ülikooli etnoloogid ja keeleteadlased kasutasid ekspeditsioone ära mitmesuguse iseloomuga algandmete kogumiseks, mida kasutati hiljem uurimistöödes." (Lk 81)

Selline käsitlus ei ütle praktiliselt midagi, kuigi tegemist oli väga olulise ettevõtmisega. Nimetatud piirkonna Saksa okupatsiooni kasutati osavalt selleks, et uurida sealsete vähemusrahvuste, peamiselt eestlaste olukorda. Nii toimus 1942. aastal ekspeditsioon Ingerimaale (uuriti peamiselt vadjalasi), olulisem ekspeditsioon leidis aga aset 1943. aastal Ida-Peipsimaal, kus uuriti õigusteadlase IImar Arensi juhtimisel eestlaste olukorda. ${ }^{17}$ Sellega fikseeriti selle piirkonna eestlaste traagiline saatus - hävitamine nõukogude võimu poolt 1920.-1930. aastatel. IIma tollal tehtud uurimisretketa teaksime tänapäeval vaevalt Peipsi-taguste eestlaste käekäigust.

Teise näitena saab tuua nõukoguliku Eesti ajaloo õpiku koostamise küsimuse, millel Laas üsna pikalt peatub, kuigi ta teemat ei valda. Tähtis on teada, kelle korraldusel ja miks tuli seda teha, milline oli selles ülesande tegelike täitjate - ajaloolaste roll ning kuidas kõik tegelikult toimus.

Uut Eesti ajaloo käsitlust vajati Eesti ajaloo õpetamise jätkamiseks koolis ning Eesti NSV ajaloo õpiku komisjon moodustati EK(b)P Keskkomitee büroo otsusega 9. septembrist 1945, sellesse kuulusid peamiselt TRÜ õppejõud Hans Kruus, Richard Kleis, Harri Moora ja Hilda

16 Jaan Roos. Ülikooli õppejõudude kultuurivarad sõjatules. - Akadeemia 1989, nr 2, 3, Ik 280-292, 517-530.

17 IImar Arens. Õigusajaloolase mälestusi. - Akadeemia 1992, nr 11, Ik 2297-2310. 
Moosberg ning Eesti NSV Haridusministeeriumi metoodik Villem Orav. Hoolimata nõuetest viivitati raamatu koostamisega ja on üsna ilmne, et marksistlikku Eesti ajaloo käsitlust ei tahetud lihtsalt kirjutada. Õpiku kõrval jäeti täitmata teinegi tellimustöö („Eesti kodanlik vabariik 1918.-40. aastal"). ${ }^{18}$

Kokkuvõttes jääb üle nentida, et see raamat on tõesti üks samm Eesti okupatsioonide aegse teaduspoliitika üldistamise teel - sisult sotsialistlik, vormilt rahvuslik ja üldsegi mitte tõsiselt võetav.

Anu Raudsepp, PhD, Tartu Ülikooli lektor. Peamised uurimissuunad: haridus- ja teadusajalugu, ajaloodidaktika. Kontakt: anu.raudsepp@ut.ee

Hillar Toomiste, elektroonikainsener, Eesti Maaülikooli doktorant. Peamine uurimissuund: keskkonnatehnoloogia. Kontakt: hillar.toomiste@gmail.com

18 Anu Raudsepp. Ajaloo õpetamise korraldus Eesti NSV eesti õppekeelega üldhariduskoolides 1944-1985. Dissertationes Historiae Universitatis Tartuensis. 10. Tartu: Tartu Ülikooli Kirjastus, 2005, Ik 60-65. 